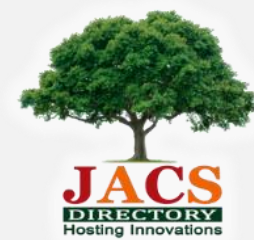

Journal of Nanoscience and Technology

\title{
Advancement in the Utilization of Nanocatalyst for Transesterification of Triglycerides
}

\author{
Dhiraj Kumar ${ }^{1}$, Sanjeev Sharma ${ }^{1}$, Niti Srivastava ${ }^{2}$, Sudeep Shukla ${ }^{3}$, Kumar Gaurav,,* \\ ${ }^{1}$ Department of Mechanical Engineering, Amity School of Engineering and Technology, Amity University, Gurugram - 122 413, Haryana, India. \\ ${ }^{2}$ Amity Institute of Biotechnology, Amity University, Gurugram, Gurugram - 122 413, Haryana, India. \\ ${ }^{3}$ Amity School of Earth and Environmental Science, Amity University, Gurugram - 122 413, Haryana, India.
}

\section{ART IC LE DETAILS}

\section{Article history:}

Received 13 April 2018

Accepted 22 April 2018

Available online 02 May 2018

\section{Keywords:}

Biodiesel

Transesterification

Nano Catalyst

Heterogeneous Catalyst

Graphene Oxide

\begin{abstract}
A B S T R A C T
Biofuels are emerging as an alternative fuel to replace the conventional one. Biodiesel production is carried out by the transesterification process where catalyst plays an important role in the production of biodiesel. The reaction is catalyzed by either homogeneous catalyst or heterogeneous catalyst as the selection of suitable catalyst depends upon the amount of free fatty acid present in oil. Since past few decades focus was made on homogeneous catalyst for the production of biodiesel but slowly the trend has been changed as heterogeneous catalyst is becoming more promising catalyst for the production of biodiesel due to its properties which can overcome the problems faced by the homogeneous catalyst. Heterogeneous catalysts have been effective way to produce biodiesel but has drawback of being sensitive to free fatty acids (FFA) and low grade feed stock. This paper gives overview of the production of biodiesel with different heterogeneous catalyst consisting of carbon catalyst such as $\mathrm{CaO}$ based catalyst, carbon nano tubes (CNT) and graphene oxide (GO), activated carbon and solid acid catalyst. The utilization of heterogeneous catalyst provides a greener and cheaper synthesis of production of biodiesel.
\end{abstract}

\section{Introduction}

Fossil fuels are the major source of energy which satisfies the $90 \%$ of world's energy demand. As excessive usage or consumption of fossil fuels, this has raised the alarm of depletion in natural resources, increase in greenhouse gas emission and global warming. The experts predict that available sources of fossil fuels will run out by 2050 because their consumption is more faster than their natural production [1] while the energy demand will reach to 30 Terawatt (TW) in near future. Due to this the researchers are focusing on other means of renewable energy sources which will meet the half of the world's energy need and will reduce the greenhouse gas emissions. The energy demand has accounted a rapid growth of industrialization in the $19^{\text {th }}$ century. The energy is the main component for the existence of life on earth. The main reason for finding the alternate source of energy is due to increase in demand of natural resources and in limited amount around the world [2].

Biofuels is produced from the contemporary process known as biological processes, such as agriculture and anaerobic digestion rather than geological process such as fossil fuels i.e., coal and petroleum. Bio fuels can be derived from plants, bio-waste or indirectly from agriculture, commercial and domestic industrial wastes. Other renewable biofuels are produced through the use or conversion of bio mass. The bio mass can be converted to convenient energy containing substance in three different ways; thermal conversion, chemical conversion and bio chemical conversion. This bio mass can result fuel in solid, liquid and gaseous forms [3]. Among the renewable fuels, biodiesel has a significant position which can be produced from the bio-sources such as vegetable oils, animal fats, soybean oil and algae lipids. The properties biodiesel possess is it's non toxicity and biodegradability in nature, has high flash point, good lubricant and low gas emission with less harmful components during combustion $[4,5]$. Biodiesel has remained a good substitute for conventional fuel as it has similar physical and chemical properties to that of conventional fuel. Chemically biodiesel are known as reacting lipids with an alcohol producing fatty acids. Production of biodiesel is a great challenge as main criteria lies in the minimizing the cost of production, selection of suitable

feed stock and catalyst. As catalyst plays an important role in the production of biodiesel [2].

Currently there are two types of catalyst used for the production of biodiesel catalyzed by the reaction- homogeneous and heterogeneous catalysts. The technologies implemented for the production of biodiesel are mostly based on homogeneous catalyst [6]. As the homogeneous catalyst are inseparable as it gets fully dissolved with the two reacting chemicals and cannot be reused which makes it an expensive catalyst. It leads the researchers around the world to focus towards the heterogeneous catalyst for the production of bio diesel. The heterogeneous catalyst are non-corrosive, eco-friendly in nature, can be easily separated from products, tunable, selective, capable of producing a clear solution of biodiesel and reused with or without regenerating them makes it more convenient for the production of biodiesel compared to homogeneous catalysts [7].

\section{Synthesis of Biodiesel from Nano and CaO Based Catalyst}

\subsection{Nano Catalyst}

In last decade, researchers have been searching for advanced functional and low cost nano materials which include carbon nano tubes, nano fibers, nano clays, nano composites etc. for different applications. The geometrical dimensions of nano material is less than $100 \mathrm{~nm}$ and the nano particles as spherical in shape having diameter less than $100 \mathrm{~nm}$ can play an important role in catalysis process [6].

There are two types of process for the synthesis of nanoparticlephysical and chemical process. The physical method requires large capital cost with reduced environmental impact whereas chemical process is cheap due to reduced energy input. The characteristics that nano catalyst should possess is extremely high activity, low energy consumption and long life which can be achieved by controlling the size, shape, spatial distribution, surface composition and electronic structure with thermal and chemical nano component stability [8]. Its advantages in chemical industries can be specified as energy efficiency, reduced global warming; optimum feed stock utilization and minimum chemical waste. A high degree of catalyst selectivity plays an important role in catalysis process so heterogeneous catalyst makes a prime source of energy saving technology [8]. Heterogeneous catalyst consist of numerous favorable nanoparticle catalytic properties such as high activity, surface reactivity, 
large pore size and large surface area they are preferable catalyst for the production of biodiesel. A typical heterogeneous catalyst consist few nanoparticle dispersed on highly porous material having surface area upto $250 \mathrm{~m}^{2} / \mathrm{g}$ [9].

The different solid catalyst which have been tested in biodiesel in nano form are: $\mathrm{Fe}_{3} \mathrm{O}_{4}, \mathrm{Ca} / \mathrm{Al} / \mathrm{Fe}_{3} \mathrm{O}_{4}$, aluminum powder, $\mathrm{KF} / \mathrm{Al}_{2} \mathrm{O}_{3}$ etc., [10-12]. Among them $\mathrm{CaO}$ based catalyst is efficient catalyst for the use in nano form for the transesterification process of different oil feed stocks for the production of biodiesel.

\subsection{CaO catalyst in Synthesis of Biodiesel}

The $\mathrm{CaO}$ based catalyst is conducted in two ways; preparation and activation of nano particles. In the first step the methods include are thermal decomposition, impregnation mixing and co-precipitation and in the second step calcinations is done to the produce nano particles in order to achieve the specific catalytic activity. This increases the surface area of $\mathrm{CaO}$ catalyst which can be employed for the transesterification of various oil feed stocks. $\mathrm{CaO}$ has greatest potential for transesterification process because of its catalytic activity such as nature, size and specific surface area and their reaction condition. There are four forms of nano $\mathrm{CaO}$ such as neat $\mathrm{CaO}$, doped $\mathrm{CaO}$, loaded $\mathrm{Cao}$ and waste $\mathrm{CaO}$ which are used as catalyst in synthesis of biodiesel form different oil feed stocks [6]. Doped $\mathrm{CaO}$ and loaded $\mathrm{CaO}$ based catalyst is more preferred than neat $\mathrm{CaO}$ because it easily form hydrogen bond with methanol and glycerol, complicates the post treatment process and phase separation which increases the cost of production.

It has been found out that neat $\mathrm{CaO}$ when used in poultry fat with alcohol: oil molar ratio of $10: 3$ at room temperature gives $100 \%$ yield conversion [13] and in palm oil as feed stock with 15:1 alcohol:oil molar ratio at $60{ }^{\circ} \mathrm{C}$ it gives $95.7 \%$ yield conversion which is lowest in all feed stock [14]. In doped $\mathrm{CaO}$ with used cotton seed oil as feed stock with 3:18:1 alcohol:oil molar ratio at $35-65{ }^{\circ} \mathrm{C}$ gives $100 \%$ yield conversion whereas with rapeseed oil with 6:1-12:1 alcohol: oil molar ratio at 70-90 ${ }^{\circ} \mathrm{C}$ gave $93 \%$ yield conversion which were lowest in all other feed stock $[6,15]$. In loaded $\mathrm{CaO}$ the higher yield was with jatropha oil with 99\%, 15:1 alcohol: oil molar ratio at $70{ }^{\circ} \mathrm{C}$ and lowest was recorded with soybean oil with $97.8 \%$ yield at $60^{\circ} \mathrm{C}$ and $15: 1$ alcohol:oil molar ratio $[6,16]$.

\section{Synthesis of Activated Carbon}

Activated carbon is a form of carbon processed to have small, low volume pores that increase the surface area available for adsorption or chemical reaction. The activated carbon is commercially used in waste water treatment which is produced from coconut shell, wood and lignite [1]. As the waste water treatment is less profitable compared to other industrial use, it is always preferable to reduce the cost of treatment of waste water. Since the last decade numerous biowaste has been identified for the production of low cost adsorbent and number of studies has been conducted to determine the characteristics and efficiencies of activated carbon which is produced from different biowaste in removal of different pollutants from waste water.

The synthesis of activated carbon from biomass are generally involves pre-treatment of the sample, crushing, drying and sieving with carbonization of biomass in dry inert gas atmosphere which eliminates the volatile matters and tars. This leads the formation of biochar which can be referred as charcoal. The use of hydrothermal carbonization is gaining popularity in preparation of activated carbon. In this process biomass is mixed with water or reagent solution before carbonization process [17]. It has been stated that hydrothermal carbonization is more advantageous than conventional one as in this biomass drying process is not required. A lower temperature is used in this process as the pressure from the steam present in the closed system acts as an extra driving force to convert the biomass to hydro char. The acidic gases such as $\mathrm{CO}_{2}, \mathrm{NO}_{2}, \mathrm{SO}_{2}$ etc. produced during the heating may react with water to form an acidic solution, thus treatment is needed to eliminate such gaseous pollutant. Thus presence of several functional groups on the hydrochar as reported which increases the higher adsorption capacity of contaminants [18].

Several studies have showed that presence of these functional group improves the adsorption of heavy metals on hydro char despite having lower surface area compared to activated carbon [19]. There are two types of activation required such as physical and chemical activation to activate the carbonized material after carbonization of biomass. The physical activation is mostly performed by passing inert gas such as $\mathrm{CO}_{2}, \mathrm{~N}_{2}$ etc. or steam through the sample at high temperature [20]. This limit the conversion of carbon material into $\mathrm{CO}_{2}$ through oxidation which increases the yield of activated carbon compare to activation in air. In chemical activation, activating reagent such as acid or base is added to the hydrochar prior to heating followed by washing to neutralize the $\mathrm{pH}$ of activated carbon formed. $\mathrm{KOH}$ is the reagent used in chemical activation. Some researchers attempted to modify the synthesis method of activated carbon. In chemical activation the biomass is mixed with chemical activating reagent prior to pyrolysis at high temperature which is known as one step pyrolysis where as in certain studies two step of pyrolysis of biomass was carried out where carbonization at lower temperature precedes addition of chemical activating agent $[21,22]$. The two step pyrolysis increased microporosity and surface area of activated carbon which lead to higher adsorption capacity.

The preparation of activated carbon using a three step process was done by Tran et al. [21]. It was observed that activated carbon prepared by three step process showed a higher adsorption performance towards cationic dye than activated carbon prepared using one step and two-step process. So the three stage synthesis is considered a more effective approach in activated carbon preparation.

\subsection{Pollutants Removal using Activated Carbon Derived from Biowaste}

Activated carbon have been proven to be effective in removal of various pollutants from aqueous solution including dyes, pharmaceutical and personal care products, heavy metals and organic pollutants.

\subsubsection{Dyes}

Dyes are identified to be the one of the heavy pollutants of water bodies due to the use of large amount of colorings required in clothing, paper products, paints and plastics. Most dye molecules are resistant to degradation in water due to their complex structures. This causes the harmful effect on photosynthesis of aquatic plants and causes mutagenic and carcinogenic effects to human bodies [23, 24]. A large number of studies are carried out on removal of dyes especially methylene blue (MB) [25]. The very low adsorption capacities of methylene blue on biomass without activation was recorded on sweet lemon peel i.e., $0.66 \mathrm{mg} / \mathrm{g}$, waste egg shell and membrane i.e., $94.9 \mathrm{mg} / \mathrm{g}[26,27]$.

Pradhananga et al. [28] reported that high adsorption of two dyes which was used in wool carpet dyes, lanasyn orange at $2.60 \times 10^{3} \mathrm{mg} / \mathrm{g}$ and lanasyn gray at $2.60 \times 10^{3} \mathrm{mg} / \mathrm{g}$ on activated carbon derived from chemically activated bamboo cane.

\subsubsection{Heavy Metals}

The hazards brought by heavy metals and anions in water have raised concern among the public. The consumption of metal and anions usually causes severe damage to human body, chronic effects instead of acute effects [29]. The efficiency of adsorption in removal of contaminants from waste water through activated carbon is undesirable due to the low affinity towards heavy metals [30]. So the development of other adsorbents from biomass waste should be vital to minimize the heavy metal ions from entering the water bodies. The activated carbon produced from Loblolly pine chips removes $167.3 \mathrm{mg} / \mathrm{g}$ of $\mathrm{Cd}^{2+}$ pollutant, radish press cake removes $500 \mathrm{mg} / \mathrm{g}$ of $\mathrm{Pb}^{2+}$ pollutant which is the highest rate of removal and the lowest was recorded with Rice husk, $1.5 \mathrm{mg} / \mathrm{g}$ of $\mathrm{Cr}^{6+}$ pollutant [29].

\subsubsection{Organic Pollutant}

Palm oil is one of the main vegetable oil used globally and Malaysia produces 39\% of the world palm oil. Despite the huge economic benefit, treatment of palm oil mill effluent remains main concern $[29,31]$. The decomposition of organic substance in palm oil mill effluent in rivers produces harmful component and threat to aquatic life. The common treatment process acquired is pond system which requires a large land area and long hydraulic retention time [32]. The adsorption is used in polishing of treated palm oil mill effluent prior to discharge to meet the waste water discharge order. The adsorbent derived from sugar cane bagasse removes $97.83 \%$ of color, $88.14 \%$ of COD and $47.25 \%$ of $\mathrm{NH}_{3}-\mathrm{N}$ which is an efficient adsorbent and lowest was recorded with coconut shell comprising $39 \%$ of TS's, $66 \%$ of COD and $61 \%$ of color in palm oil mill effluent [29].

\subsubsection{Pharmaceutical and Personal Care Products}

The presence of pharmaceuticals and personal care products waste from these industries in waste water is a growing concern as these compounds are resistant to biodegradation. The emerging contaminants such as carbamaze pine, naproxen, diclofenac and ibuprofen that require close monitoring due to potential effect on human health [33]. The adsorbate prepared from waste tea residue in $\mathrm{H}_{3} \mathrm{PO}_{4}$ at $450{ }^{\circ} \mathrm{C}$ in steam removes $273.7 \mathrm{mg} / \mathrm{g}$ of oxytetracycline pollutant from PPCPs and lowest was recorded $175 \mathrm{mg} / \mathrm{g}$ when prepared in $\mathrm{H}_{3} \mathrm{PO}_{4}$ at $450{ }^{\circ} \mathrm{C}$ in $\mathrm{N}_{2}$ [34]. Also, 
the adsorbent derived from saw dust removes $334.28 \mathrm{mg} / \mathrm{g}$ of bisphenot A, $226.71 \mathrm{mg} / \mathrm{g}$ of paracetamol, $256.29 \mathrm{mg} / \mathrm{g}$ of caffine, $329 \mathrm{mg} / \mathrm{g}$ of 2naphtol, $272.28 \mathrm{mg} / \mathrm{g}$ of o-nitrophenol, $150.87 \mathrm{mg} / \mathrm{g}$ of Resorcinol and $254.36 \mathrm{mg} / \mathrm{g}$ of Hydroquinone contaminant from PPCPs [35].

\subsection{Advancement of Adsorption of Contaminants onto Activated Carbon}

Recent advancement has been made on adsorption of contaminant by synthesis of magnetic activated carbon involved treatment of precursor with metal based reagent. This is done to deposit the ions on the precursor surface and inside the pores. In a study done by Rattanachueskul et al. [36] shows that it is possible to synthesis magnetic hydrochar from biomass with desirable pollutant removal property despite of having lower surface area available for adsorption when compared to activated carbon.

Modification of activated carbon with magnetic material was also studied as such material facilitates the adsorption of some contaminants that can be hardly removed by conventional activated carbon.

\section{Heterogeneous Catalyst Derived from Biomass for the Production of Biodiesel}

Biodiesel is chemically known as fatty acid methyl ester (FAME) by chemically reacting feed stock with catalyst. The production of biodiesel is carried out through transesterification process with homogeneous or heterogeneous catalyst. The biodiesel production was focused on edible vegetable oil as feed stock such as palm oil, soybean oil, sun flower oil, algae oil etc. Non edible oil such as jatropha oil, waste cooking oil, algae oil and animal fat are considered as reliable feed stock as these cuts the cost of procurement as compared to edible oil. Biodiesel can be produced by either transesterification of triglycerides with short chain alcohol or esterification of free fatty acid (FFA) [37-39].

At present time there are several methods for the production of biodiesel such as direct use and blending of raw oil, dilution, micro emulsion, pyrolysis and transesterification [40]. Among all these method transesterification is the most suitable, easiest and cost effective approach for the production of biodiesel. The catalyst for the transesterification reaction can be alkali, acid or enzyme [41]. FAME is generally produced at industrial scale by using homogeneous catalyst such as $\mathrm{NaOH}, \mathrm{KOH}$ and $\mathrm{H}_{2} \mathrm{SO}_{4}$. The use of homogeneous acid and base catalyst will lead to corrosion of reactor and soap formation which leads to formation of stable emulsion and Saponification with low yield conversion [42].

A homogeneous base catalyst has been currently widely used in industries for the production of biodiesel in large scale. However the homogeneous catalyst reaction is highly sensitive to the presence of free fatty acid (FFA) and water. In a decade heterogeneous catalyst has gain interest in the production of biodiesel. The heterogeneous catalyst does not dissolve in the reacting chemical which makes it easier to separate and reusable [43]. The heterogeneous catalyst offers several benefits such as non-corrosive, easy separation and longer catalyst life [44, 45]. In heterogeneous catalyst such as $\mathrm{Ca}, \mathrm{Na}, \mathrm{Mg}$ and $\mathrm{K}$ which are usually prepared in the form of millimetric spherical particles and nanostructure material which increases the surface area of catalyst as well as the catalytic activities. The major drawbacks of mentioned above catalyst are soap formation, leaching of catalytic active sites in reaction and high sensitivity to moisture and free fatty acid (FFA). So to overcome this limitation we have to perform acid pretreatment process for low quality feed stock to reduce FFA and development of active and low cost heterogeneous catalyst $[46,47]$

\subsection{Heterogeneous Alkali/ Base Catalyst Derived from Biomass}

\subsubsection{Biomass Ashes}

A biomass ash is a solid based catalyst which can be separated and reused in the process. Organic compound contain high amount of carbon, oxygen and metal salt including $\mathrm{K}, \mathrm{Na}, \mathrm{Mg}$, $\mathrm{Ca}$ [48]. Upon combustion at high temperature the carbon and oxygen content reduces, leaving alkali metal oxides such as $\mathrm{CaO}, \mathrm{K}_{2} \mathrm{O}, \mathrm{MgO}$ and the main ingredients in ashes [49]. High presence of basic strength oxides in the ashes increases its catalytic property to produce biodiesel [50].

In a study by Ofori- Boateng and Lee [51] reported that, potash as the potential catalyst for biodiesel production. In potash or potassium carbonate $\left(\mathrm{K}_{2} \mathrm{CO}_{3}\right)$ or potassium chloride $(\mathrm{KCl})$ a byproduct of biomass combustion. The inorganic derived potash has high catalytic ability and is used as a base catalyst in biodiesel production, but their synthesis is rather hazardous, environmentally damaging and unsuitable. In a study done by Deka and Basumatary [52], Musa balbisiana colla ash when used with Cascabela thevetia (Thevetia peruviana) seed oil at $32{ }^{\circ} \mathrm{C}$ for $3 \mathrm{hr}, 20 \mathrm{wt} \%$ catalyst and methanol:oil molar ratio of $20: 1$ gave $96 \%$ of yield conversion which makes it a promising catalyst for the production of biodiesel.

\subsubsection{Waste Shell}

The use of heterogeneous catalyst for the production of biodiesel is advantageous because it will not mix with the reacting chemicals and can be easily separated and reused. The search for greener catalyst to replace the use of conventional catalyst has been studied by numerous researchers. Mostly they utilized the catalyst derived from calcium carbonate enriched organic waste such as waste shell and animal bones. Upon combusting calcium carbonate $\left(\mathrm{CaCO}_{3}\right)$ at high temperature it will be converted to calcium oxide $(\mathrm{CaO})$ which is a highly active base catalyst for biodiesel production. Waste shell mainly composed of $\mathrm{CaCO}_{3}$ with trace amount of magnesium carbonate $\left(\mathrm{MgCO}_{3}\right)$, strontium carbonate $\left(\mathrm{SrCO}_{3}\right)$, calcium phosphate, organic substance and water [53].

Most of the waste shell does not have practical use and no value so they are discarded by marine product manufacturers and local restaurants into land fill [54]. The high amount of $\mathrm{CaCO}_{3}$ in waste shell is the source for synthesis of $\mathrm{CaO}$ as a catalyst. The various types of $\mathrm{CaCO}_{3}$ enriched organic wastes has been investigated as a potential catalyst for the production of biodiesel including waste shell, waste egg shell [55] , waste coral fragment [56], waste fish scale [57] and waste animal bones [58, 59].

The study conducted by Boey et al. [60] on cokle shell of Tegillarca granosa (Anadara granosa) in palmolein oil in production of biodiesel. The waste shell was calcinised at $900{ }^{\circ} \mathrm{C}$ for $2 \mathrm{hr}$ which produced the active catalyst. Thus the transesterification process resulted in $97.48 \%$ yield in 3 hr reaction time. In another study done by Boro et al. [61] the waste shell of Pyrgostylus striatulus was found to be promising catalyst for biodiesel production using mustard oil through transesterification reaction at $65^{\circ} \mathrm{C}$ for $3 \mathrm{hr}, 3 \mathrm{wt} \%$ catalyst and methanol:oil molar ratio of 9:1 gave $93.3 \%$ yield conversion.

\subsubsection{Activated Carbon Catalyst}

Activated carbon is a form of amorphous carbon with high porosity nature [44] which can be derived from carbon content compound such as coal, wood and coconut shell. Activated carbon is widely used in pollution controlled application such as air and gas filter, water treatment for the removal of toxic elements from it [62]. The utilization of heterogeneous catalyst may reduce the mass transfer limitation and hence increases the rate of reaction. The use of Activated carbon will reduce the cost of production [63]. Several studies have investigated the potential of biomass derived Activated carbon as catalyst with certain active metals which improves the catalytic performance.

Chakraborty et al. [55] has concluded that high amount of $\mathrm{SiO}_{2}$ and $\mathrm{Al}_{2} \mathrm{O}_{3}$ of fly ash when used in soybean oil at $70{ }^{\circ} \mathrm{C}, 5 \mathrm{hr}, 1 \mathrm{wt} \%$ catalyst with Methanol:oil molar ratio of 9:1 provides $96.9 \%$ yield conversion which is a good low cost catalyst as conventional one. Biomass ashes have potential as a good catalyst including cocoa pod husk ash [51], coconut husk ash [49] and empty palm bunch ash [64].

\subsection{Effect of Methanol to Oil Molar Ratio in Production of Biodiesel}

In a study, Amani et al. [65] reported that 90\% yield conversion in biodiesel was optimized at value of 20:1 methanol to oil molar ratio and further increase in methanol to oil molar ratio 30:1 reduces the yield conversion drastically to $65 \%$. In another findings by Phan and Phan [66] where they reported that biodiesel from waste cooking oil at 8:1 methanol to oil molar ratio gave $88 \%$ yield conversion and when $12: 1$ methanol to oil molar ratio was taken into consideration the yield conversion decreased to $82 \%$.

\subsection{Effect of Catalyst Loading in Production of Biodiesel}

In a study by Amani et al. [65], reported that the increase in FAME content with the increase in catalyst loading. It has been shown that $90 \%$ of FAME content was produced at 3wt \% catalyst loading after $3 \mathrm{hr}$ reaction time and the FAME content was decreased to $83 \%$ with $4 \mathrm{wt} \%$ catalyst loading. It was reported that solubility of methanol observed in high FFA waste cooking oil is due to low catalyst loading.

\subsection{Effect of Calcination Temperature on Catalyst Preparation}

Calcination temperature has greater influence on the catalytic property in development such as acidic site density, surface area and pore volume, molecular and crystalline structure [42]. Calcination temperature affects the performance of the catalyst as increase in calcination temperature during catalyst development decreases the FAME content significantly and reduced low catalytic activity [67]. 


\section{Advantages and Disadvantages of Solid Acid Catalyst}

The advancement achieved in heterogeneous catalyst is that it is a recyclable solid acid catalyst for the production of biodiesel. The catalyst Lewis type (mixed sulfated oxides) and Bronsted type (sulphonic acid) have exceptional advantages in esterification, transesterification reaction and high FFA contents peculiar to low grade oil. Other advantages of these catalyst are selectivity, recyclability, regeneration, elimination of washing step and minimizing if corrosion problem even in presence of acid species [68]. In spite of having encouraging result in biodiesel production by esterification reaction of solid acid catalyst are slow on transesterification process. As a result large amount of catalyst is needed for transesterification reaction. High temperature requirement and long reaction time in transesterification reactions for biodiesel production is a problem. Other limitations are leaching, product contamination, high amount of catalyst requirement and formation of side reactions such as ether formation [42].

\section{Carbon Catalyst}

\subsection{Graphene Oxide}

Graphene is referred as an atomic layer of graphite which is basic unit of fullernes and carbon nano tubes. Graphene has 2D structure consisting of single atomic layer of $\mathrm{sp}^{2}$ hybridized carbon atoms closely packing into honey comb lattice by $\sigma$ bonding. Raman spectroscopy is used to determine its number of layers [69]. Single layer transferable graphene nano sheets were first obtained by mechanical exfoliation of bulk graphite and by chemical vapour deposition (CVD). The strong oxidizing agent is the popular approaches towards graphite exfoliation to obtain graphene oxide [70]. Brodie [71] was the first researcher that discovered properties of graphite oxide [72]. Since then graphite oxide became popular among researchers because of its unique properties. The preparation of graphene oxide can be modified to produce certain functionalized graphene oxide which has lower and higher conductivity properties than pristine graphene [73, 74]. Organic solvent such as dimethylformamide, N-methyl2-pyrrolidone, tetrahydrofuran and ethylene glycol can form single layer of graphene oxide sheet when used with water [72]. Kavinkumar et al. [75] reported that graphene oxide containing more $\mathrm{sp}^{3}$ and less $\mathrm{sp}^{2}$ carbon atom which becomes nonconductive element. The recent method for obtaining graphene oxide was obtained from graphite flakes by using modified Hummers method.

The basic properties of graphene are optical, mechanical, thermal, electronic, physical and chemical. There are various synthesis methods for graphene such as mechanical exfoliation, chemical derived, chemical vapor deposition, arc discharge, epitaxial growth on $\mathrm{SiC}$ and it can be synthesis by different methods by unzipping CNT with strong oxidizing agent, laser irradiation or plasma etching [76,72]. Graphene oxide has mechanically strong and chemically stable structure due to high $\mathrm{C}-\mathrm{C}$ bond and most carbon atoms are in higher oxidation states. This structure is capable of protecting active sites of catalyst. Graphene oxide can be obtained at low cost on large scale by using graphite and graphite oxide [7]. Graphene oxide can also be synthesis from waste material (like waste plastics, biomass wastes, wood, leaf, animal bones etc.).

In a study done by Nongbe Medy et al. [77] the synthesis of sulfonated graphene catalyst was done for the transesterification of palm oil with methanol into fatty acid methyl esters (FAME). The catalyst was obtained by chemical exfoliation of inexpensive graphite, followed by functionalization of prepared graphene with benzenesulfonic acid functions. As temperature is an important parameter for delicate compromise between reaction conversion and catalyst stability and to determine the influence of temperature on palm oil for the production of FAME the methanol to oil molar ratio was fixed at 12:1. When the sulfonated graphene catalyst of $10 \mathrm{wt} \%$ at $25^{\circ} \mathrm{C}$ for $14 \mathrm{hr}$ was taken into consideration $30 \%$ yield conversion was recorded. Similarly at $50{ }^{\circ} \mathrm{C}$ it was $37 \%$ conversion, at $80^{\circ} \mathrm{C}$ it was $68 \%$, at $100{ }^{\circ} \mathrm{C}$ it was $78 \%$ and at $120{ }^{\circ} \mathrm{C}$ it did not modify the mixture composition. In general high volume of methanol shifts the chemical reaction for the formation of FAME. When the amount of methanol: oil molar ratio was increased from 12:1 to 20:1 with catalyst loading of $10 \mathrm{wt} \%$ at $100{ }^{\circ} \mathrm{C}$ for $10 \mathrm{hr}$ gave $98 \%$ yield conversion.

The synthesis of graphene oxide can be processed from natural graphite powder through modified Hummers method. The study of Cheng Jun et al. [78] investigated the catalytic action of graphene and its derivatives for the conversion of lipids from wet microalgae into biodiesel is done by four heterogeneous catalyst graphene oxide, sulfonated graphene, sulfonated graphene oxide and sulfonated active carbon. The catalysts $5 \mathrm{wt} \%$ (of the mixture) at $90{ }^{\circ} \mathrm{C}$ for $40 \mathrm{~min}$ was considered for the reaction. The conversion efficiency of the microwave assisted lipid transesterification of wet microalgae using sulfonated graphene were $48.6 \%$, graphene oxide were $73.1 \%$, sulfonated graphene oxide were $84.6 \%$. Sulfonated graphene oxide showed the best catalyst performance for highest conversion efficiency of wet microalgae. In a study by Cheng Jun et al. [79] the lipids in wet microalgae was converted into FAME with solid graphene oxide catalyst. As the increase in reaction temperature from $70^{\circ} \mathrm{C}$ to $90{ }^{\circ} \mathrm{C}$ the conversion efficiency of microalgal lipids to FAME increases from $77 \%$ to $96 \%$. As the reaction temperature increases to $110^{\circ} \mathrm{C}$ the conversion efficiency decreases to $68 \%$. The conversion efficiency of microalgal lipids to FAME increases from $5.8 \%$ to $96 \%$ when the concentration of catalyst in methanol is increased from $1 \%$ to $5 \%$.

\subsubsection{Carbon Nano Tubes (CNT)}

Carbon nano tubes were discovered by Iijima in 1991 while studying the surface of graphite electrodes in an electric arc discharge. There are two forms of CNT's, Single walled carbon nano tubes (SWCNT) and multi walled carbon nano tubes (MWCNT). Single walled carbon nano tube is considered as single graphene sheet rolled into tube of single walled whereas multi walled carbon nano tube is considered as number of concentric single walled carbon nano tubes having different diameter. The synthesis of carbon nano tubes can be done by various methods such as Arc discharge, laser ablation and chemical vapor deposition (CVD) [80].

In Arc discharge method under sub atmospheric chamber carbon nano tubes is generated by providing high temperature of vaporizing carbon anodic electrode by applying direct current between two graphite electrodes. The pros and cons are it is a simple process which produces impurities such as fullernes and amorphous carbon with structure defect due to high operation temperature [81, 82]. In Laser ablation method laser beam generates high temperature to gasify the carbon target mostly a graphite pellet with certain amount of Co and $\mathrm{Ni}$ as catalyst. During vaporization of carbon, inert gas is pumped through tube to collect carbon nano tubes on the cold finger. Its pro's and con's are it produces high and pure quality of carbon nano tubes but the quality depends upon the synthesis condition such as laser properties, carbon source composition etc., [81, 82]. In Chemical vapor deposition (CVD) carbon nano tubes are produced from hydrocarbons such as methane which initially adsorb on catalytic particle surface followed by decomposing into carbon atoms under inert atmosphere. Later the carbon atoms is diffused into catalyst substrate, after achieving supersaturated state the precipitated carbon atoms serves as seed points for carbon nano tubes nucleation and growth. Its pro's are large scale production, easy reaction control, pure carbon nano tubes and carbon nano tube properties such as orientation, diameter, alignment and length. The con's are it is expensive and energy consuming [83].

In a study done by Shu Qing et al. [84] multi walled carbon nano tube was produced by $\mathrm{C}_{3} \mathrm{H}_{6}$ decomposition on $\mathrm{Fe} / \mathrm{Mo} / \mathrm{Al}_{2} \mathrm{O}_{3}$ catalyst in a fluidized bed reactor with a sintered porous filter plate at its bottom. The plate acts as carrier for $\mathrm{Fe} / \mathrm{Mo} / \mathrm{Al}_{2} \mathrm{O}_{3}$ catalyst before it began to fluidize. As the waste animal fats and vegetable oil contains lot of fatty acids, the main component in this is oleic acid which was used to substitute the animal fat and vegetable oil. $\mathrm{SO}_{4}{ }^{2-} / \mathrm{MWCNTS}, \mathrm{SO}_{4}{ }^{2-} / \mathrm{MWCNT}$ and $\mathrm{Al}^{3+}$ $\mathrm{SO}_{4}^{2-} / \mathrm{SWCNTs}, \mathrm{Al}^{3+}-\mathrm{SO}_{4}^{2-} / \mathrm{C}$ were used as catalyst for the production of biodiesel. The experimental study of the catalyst $\mathrm{SO}_{4}{ }^{2-} / \mathrm{MWCNTs}$, $\mathrm{SO}_{4}^{2-} /$ MWCNTs as follows:- methanol:oleic acid molar ratio of $12: 1$, catalyst $0.5 \mathrm{wt} \%$ for $6 \mathrm{hr}$ at $65^{\circ} \mathrm{C}$. The experimental study for catalyst $\mathrm{Al}^{3+}$ $\mathrm{SO}_{4}^{2-} / \mathrm{MWCNTS}, \mathrm{Al}^{3+}-\mathrm{SO}_{4}^{2-} / \mathrm{SWCNTS}$ and $\mathrm{Al}^{3+}-\mathrm{SO}_{4}^{2-} / \mathrm{C}$ as follows:methanol:oleic acid molar ratio of $12: 1$, catalyst $0.9 \mathrm{wt} \%$ for $7 \mathrm{hr}$ at $65^{\circ} \mathrm{C}$. After the experimentation process it has been found that the yield conversion was $95 \%$ with oleic acid with $\mathrm{Al}^{3+}-\mathrm{SO}_{4}{ }^{2-} / \mathrm{MWCNT}$ catalyst and $80 \%$ conversion with $\mathrm{Al}^{3+}-\mathrm{SO}_{4}{ }^{2-} / \mathrm{SWCNTs}$ or $\mathrm{Al}^{3+}-\mathrm{SO}_{4}{ }^{2-} / \mathrm{C}$ catalyst. Further it was reported that the conversion of oleic acid was still high at $81.8 \%$ when $\mathrm{Al}^{3+}-\mathrm{SO}_{4}{ }^{2-} / \mathrm{MWCNT}$ catalyst was recycled for eight times which indicates it has high catalytic stability. In another study by Deep et al. [85] the lipase was conjucated with MWCNTs by chemical reaction. The lipaseMWCNT catalyst has been employed for the production of FAME through methanolysis of crude jatropha oil. The yield of FAME production increases linearly with increase in the catalyst support fraction in reaction time of $1 \mathrm{hr}$. The desired yield $90 \%$ of product was achieved when using $15 \%$ immobilized catalyst and the conversion of non-immobilized lipase was only in the range of $10-15 \%$.

\section{Conclusion}

This review considers the potential of using heterogeneous catalyst for the production of biodiesel as it has various advantages than homogeneous catalyst. It demonstrate the different form of nano catalyst and their synthesis with focus on $\mathrm{CaO}$ based catalyst such as neat, doped, loaded and waste with the conversion rate of each catalyst with low grade 
feed stock for the production of biodiesel. The focus has been made on other catalytic substance too such as alkali/base catalyst from biomass for the synthesis of heterogeneous catalyst and carbon nano tubes for the production of biodiesel. Heterogeneous catalyst offers several benefits over homogeneous catalyst such as non-corrosive, easy separation, reusability and longer catalyst life. This makes heterogeneous catalyst a promising catalyst for the production of biodiesel. The heterogeneous alkali/base catalyst is derived from biomass such as biomass ashes, waste shell and activated carbon catalyst to compare the prominent and suitable catalyst for the production of biodiesel. Also the focus has been made on the use of activated carbon in different material components to remove the various pollutants from aqueous solution and organic pollutants. The production of biodiesel through low grade feed stock by heterogeneous solid acid catalyst and carbon nano tubes has been reviewed with the effect of methanol to oil molar ratio, catalyst loading and calcinations temperature on solid acid catalyst with various properties of graphene oxide and carbon nano tubes (SWCNTs and MWCNTs) with their respective yield conversion. The future aspect of heterogeneous catalyst is that when it is coupled with low grade feedstocks it could become a new effective route to replace the conventional fuel as energy source with low cost of production.

\section{References}

[1] A. Demirbas, Progress and recent trends in biodiesel fuels, Energy Conv. Manag. 50 (2009) 14-34.

[2] G. Baskar, R. Aiswarya, Trends in catalytic production of biodiesel from various feedstocks, Renew. Sustain. Energy Rev. 57 (2016) 496-504.

[3] Z.M.A. Bundhoo, R. Mohee, Ultrasound-assisted biological conversion of biomass and waste materials to biofuels: A review, Ultraso. Sonochem. 40(A) (2018) 298-313.

[4] M.P. Dorado, E. Ballesteros, J.M Arnal, J. Gomez, F.J. Lopez, Exhaust emissions from diesel engine fueled with transesterified waste olive oil, Fuel 82(11) (2003) 1311-1315.

[5] C.Y. Lin, H.A. Lin, L.B. Hung, Fuel structure and properties of biodiesel produced by peroxidation process, Fuel 86(12-13) (2006) 1743-1749.

[6] I.B. Banković-Ilić, M.R. Miladinović, O.S. Stamenković, V.B. Veljković, Application of nano CaO-based catalysts in biodiesel synthesis, Renew. Sustain. Energy Rev. 72 (2017) 746-760.

[7] T.M.M. Marso, C.S. Kalpage, M.Y. Udugala-Ganehenege, Metal modified graphene oxide composite catalyst for the production of biodiesel via preesterification of Caophyllum inophyllum oil, Fuel 199 (2017) 47-64.

[8] H.H. Kung, C.M. Kung, Nanotechnology: applications and potentials for heterogeneous catalysis, Catal. Today 97(4) (2004) 219-224.

[9] L. Filliponni, Applications of nanotechnology: catalysis, FP6 nanocap report, European commission under the sixth framework program, Belgium, 2007.

[10] Tamilmagan, A. Maheswari, P. Bijesh, A. Gopal, Biodiesel production from waste cooking oil using green synthesized nano $\mathrm{Fe}_{2} \mathrm{O}_{3}$ and $\mathrm{CuO}$ impregnated nano $\mathrm{Fe}_{3} \mathrm{O}_{4}$, Int. J. Chem. Tech. Res. 8(5) (2015) 90-96.

[11] S. Tang, L. Wang, Y. Zhang, S. Li, S. Tian, B. Wang, Study on preparation of Ca/Al/ $\mathrm{Fe}_{3} \mathrm{O}_{4}$ magnetic composite solid catalyst and its application in biodiesel transesterification, Fuel Pro. Tech. 95 (2012) 84-89.

[12] G. Amini, G.D. Najafpour, S.M. Rabiee, A.A. Ghoreyshi, Synthesis and characterization of amorphous nano-alumina powders with high surface area for biodiesel production, Chem. Eng. Tech. 36 (2013) 1708-1712.

[13] C.R.V. Reddy, R. Oshel, J.G. Verkade, Room-temperature conversion of soybean oil and poultry fat to biodiesel catalyzed by nanocrystalline calcium oxides, Energy Fuels 20(3) (2006) 1310-1314.

[14] B. Yoosuk, P. Udomsap, B. Puttasawat, P. Krasae, Modification of calcite by hydration-dehydration method for heterogeneous biodiesel production process: The effects of water on properties and activity, Chem. Eng. Jour. 162(1) (2010) 135-141.

[15] S. Hu, L. Wen, Y. Wang, X. Zheng, H. Han, Gas-liquid countercurrent integration process for continuous biodiesel production using a microporous solid base $\mathrm{KF} / \mathrm{CaO}$ as catalyst, Biores. Tech. 123 (2012) 413-418.

[16] Y. Zu, J. Tang, W. Zhu, M. Zhang, G. Liu, et al., Graphite oxide-supported CaO catalysts for transesterification of soybean oil with methanol, Bioresour. Technol. 102(19) (2011) 8939-8944.

[17] M.A. Islam, M.J. Ahmed, W.A. Khanday, M. Asif, B.H. Hameed, Mesoporous activated carbon prepared from $\mathrm{NaOH}$ activation of rattan (Lacosperma secundiflorum) hydrochar for methylene blue removal, Ecotoxicol. Environ. Saf. 138 (2017) 279-285.

[18] Z. Liu, F.S. Zhang, J. Wu, Characterization and application of chars produced from pinewood pyrolysis and hydrothermal treatment, Fuel 89 (2) (2010) 510514.

[19] N. Zhou, H. Chen, J. Xi, D. Yao, Z. Zhou, Y. Tian, et al., Biochars with excellent $\mathrm{Pb}(\mathrm{II})$ adsorption property produced from fresh and dehydrated banana peels via hydrothermal carbonization, Bioresour. Technol. 232 (2017) 204-210.

[20] G. Selvaraju, N.K.A. Bakar, Production of a new industrially viable greenactivated carbon from Artocarpus integer fruit processing waste and evaluation of its chemical, morphological and adsorption properties, J. Cleaner Prod. 141 (2017) 989-999.

[21] H.N. Tran, S.J. You, H.P. Chao, Fast and efficient adsorption of methylene green 5 on activated carbon prepared from new chemical activation method, J. Environ. Manage. 188 (2017) 322-336.
[22] A. Zubrik, M. Matik, S. Hredzák, M. Lovás, Z. Danková, M. Kováčová, et al., Preparation of chemically activated carbon from waste biomass by single stage and two-stage pyrolysis, J. Cleaner Prod. 143 (2017) 643-653.

[23] A. Regti, M.R. Laamari, S.E. Stiriba, M.E. Haddad, Use of response factorial design for process optimization of basic dye adsorption onto activated carbon derived from Persea species, Microchem. Jour. 130 (2017) 129-136.

[24] N. Alizadeh, M. Mahjoub, Removal of crystal violet dye from aqueous solution using surfactant modified $\mathrm{NiFe}_{2} \mathrm{O}_{4}$ as nanoadsorbent; isotherms, thermodynamics and kinetics studies, J. Nanoanal. 4(1) (2017) 8-19.

[25] P.S. Ardekani, H. Karimi, M. Ghaedi, A. Asfaram, M.K. Purkait, Ultrasonic assisted removal of methylene blue on ultrasonically synthesized zinc hydroxide nanoparticles on activated carbon prepared from wood of cherry tree: experimental design methodology and artificial neural network, J. Mol. Liq. 229 (2017) 114-124.

[26] H. Singh, G. Chauhan, A.K. Jain, S.K. Sharma, Adsorptive potential of agricultural wastes for removal of dyes from aqueous solutions, J. Environ. Chem. Eng. 5(1) (2017) 122-135.

[27] M.A.A. Khalek, M.K.A. Rahman, A.A. Francis, Exploring the adsorption behavior of cationic and anionic dyes on industrial waste shells of egg, J. Environ. Chem. Eng. 5(1) (2017) 319-327.

[28] R.R. Pradhananga, L. Adhikari, R.G. Shrestha, M.P. Adhikari, R. Rajbhandari, K. Ariga, L.K Shrestha. Wool carpet dye adsorption on nanoporous carbon materials derived from agro-product, J. Carbohydr. Res. 3(2) (2017) 12.

[29] S. Wong, N. Ngadi, I.M. Inuwa, O. Hassan, Recent advances in applications of activated carbon from biowaste for wastewater treatment: A short review, J. Cleaner Prod. 175 (2018) 361-375.

[30] A. Sigdel, W. Jung, B. Min, M. Lee, U. Choi, T. Timmes, et al., Concurrent removal of cadmium and benzene from aqueous solution by powdered activated carbon impregnated alginate beads, Catena 148(1) (2017) 101-107.

[31] J.C. Igwe, C.C. Onyegbado, A review of palm oil mill effluent (POME) water treatment, Globe J. Environ. Res. 1(2) (2007) 54-62.

[32] S.P.D. Kaman, I.A.W. Tan, L.L.P. Lim, Palm oil mill effluent treatment using coconut shellebased activated carbon: adsorption equilibrium and isotherm, MATEC Web Conf. Chem. Eng. 87 (2017) 1-6.

[33] E. Archer, B. Petrie, B. Kasprzyk-Hordern, G.M. Wolfaardt, The fate of pharmaceuticals and personal care products (PPCPs), endocrine disrupting contaminants (EDCs), metabolites and illicit drugs in a WWTW and environmental waters, J. Chemom. 174 (2017) 437-446.

[34] Y. Kan, Q. Yue, D. Li, Y. Wu, B. Gao, Preparation and characterization of activated carbons from waste tea by $\mathrm{H}_{3} \mathrm{PO}_{4}$ activation in different atmospheres for oxytetracycline removal, Jour. Taiwan Inst. Chem. Eng. 71 (2017) 494-500.

[35] P.S. Thue, E.C. Lima, J.M. Sieliechi, C. Saucier, S.L.P. Dias, J.C.P Vaghetti, et al., Effects of first-row transition metals and impregnation ratios on the physicochemical properties of microwave-assisted activated carbons from wood biomass, J. Colloid Interf. Sci. 486 (2017) 163-175.

[36] N. Rattanachueskul, A. Saning, S. Kaowphong, N. Chumha, L. Chuenchom, Magnetic carbon composites with a hierarchical structure for adsorption of tetracycline, prepared from sugarcane bagasse via hydrothermal carbonization coupled with simple heat treatment process, Bioresour. Technol. 226 (2017) 164-172.

[37] Z.A.S. Nur, Y.H. Taufiq-Yap, M.F.R. Nizah, S.H. Teo, O.N. Syazwani, A. Islam, Production of biodiesel from palm oil using modified Malaysian natural dolomites, Energy Conv. Manag. 78 (2014) 738-744.

[38] S. Sirisomboonchai, M. Abuduwayiti, G. Guan, C. Samart, S. Abliz, X. Hao, K. Kusakabe, A. Abudula, Biodiesel production from waste cooking oil using calcined scallop shell as catalyst, Energy Conv. Manage. 95 (2015) 242-247.

[39] Y.H. Taufiq-Yap, S.H. Teo, U. Rashid, A. Islam, M.Z. Hussien, K.T. Lee, Transesterification of Jatropha curcas crude oil to biodiesel on calcium lanthanum mixed oxide catalyst: effect of stoichiometric composition, Ener. Conv. Manag. 88 (2014) 1290-1296.

[40] T.M.Y. Khan, A.E. Atabani, I.A. Badruddin, A. Badarudin, M.S. Khayoon, S Triwahyono, Recent scenario and technologies to utilize non-edible oils for biodiesel production, Renew. Sustain. Energy Rev. 37 (2014) 840-851.

[41] S.H.Y.S. Abdullah, N.H.M. Hanapi, A. Azid, R. Umar, H. Juahir, H. Khatoon, et al., A review of biomass-derived heterogeneous catalyst for a sustainable biodiesel production, Rene. Sust. Ener. Rev. 70 (2017) 1040-1051.

[42] N. Mansir, Y.H.T. Yap, U. Rashid, I.M. Lokman, Investigation of heterogeneous solid acid catalyst performance on lowgrade feedstock for biodiesel production: A review, Energy Conv. Manage. 141 (2017) 171-182.

[43] A. Takagaki, M. Toda, M. Okamura, J.N. Kondo, S. Hayashi, K. Domen, M. Hara, Esterification of higher fatty acids by a novel strong solid acid, Catal. Today 116 (2006) 157-161.

[44] L.J. Konwar, J. Boro, D. Deka. Review on latest developments in biodiese production using carbon-based catalysts, Renew. Sustain. Energy Rev. 29 (2014) 546-564.

[45] M. Tariq, S. Ali, N. Khalid, Activity of homogeneous and heterogeneous catalysts, spectroscopic and chromatographic characterization of biodiesel: A review, Renew. Sustain. Energy Rev. 16 (2012) 6303-6316.

[46] A. Islam, Y.H. Taufiq-Yap, C.M. Chu, E.S. Chan, P. Ravindra, Synthesis and characterization of millimetric gamma alumina spherical particles by oil drop granulation method, Jour. Porous Mater. 19(5) (2012) 807-817.

[47] M.E. Borges, L. Díaz, Recent developments on heterogeneous catalysts forbiodiesel production by oil esterification and transesterification reactions: A review, Renew. Sustain. Energy Rev. 16 (2012) 2839-2849.

[48] R. Luque, A. Pineda, J.C. Colmenares, J.M. Campelo, A.A. Romero, J. Carlos, S. Riz L.F. Cabeza, J.C. Gores, Carbonaceous residues from biomass gasification as catalysts for biodiesel production, J. Natur. Gas Chem. 21 (2012) 246-250.

[49] V. Vadery, B.N. Narayanan, R.M. Ramakrishnan, S.K. Cherikkallinmel, S. Sugunan, D.P. Narayanan, S. Sasidharan, Room temperature production of jatropha biodiesel over coconut husk ash, Energy 70 (2014) 588-594. 
[50] A.P.S. Chouhan, A.K. Sharma, Biodiesel production from Jatropha curcas L. oil using Lemnaperpusilla Torrey ash as heterogeneous catalyst, Biomass Bioenergy 55 (2013) 386-389.

[51] C.O. Boateng, K.T. Lee, The potential of using cocoa pod husks as green solid base catalysts for the transesterification of soybean oil into biodiesel: effects of biodiesel on engine performance, Chem. Eng. Jour. 220 (2013) 395-401.

[52] D.C. Deka, S. Basumatary, High quality biodiesel from yellow oleander (Thevetia peruviana) seed oil, Biomass Bioenergy 35 (2011) 1797-1803.

[53] A. Buasri, N. Chaiyut, V. Loryuenyong, C. Wongweang, S. Khamsrisuk, Application of eggshell wastes as a heterogeneous catalyst for biodiesel production, Sustain. Energy 1 (2013) 7-13.

[54] A. Buasri, P. Worawanitchaphong, S. Trongyong, V. Loryuenyong, Utilization of scallop waste shell for biodiesel production from palm oil-Optimization using Taguchi method, APCBEE Procedia 8 (2014) 216-221.

[55] R. Chakraborty, S. Bepari, A. Banerjee, Transesterification of soybean oil catalyzedby fly ash and eggshell derived solid catalysts, Chem. Eng. Jour. 165 (2010) 798-805.

[56] W. Roschat, M. Kacha, B. Yoosuk, T. Sudyoadsuk, V. Promarak, Biodiesel productionbased on heterogeneous process catalyzed by solid waste coral fragment, Fuel 98 (2012) 194-202.

[57] R. Chakraborty, S. Bepari, A. Banerjee, Application of calcined waste fish (Labeo rohita) scale as low cost heterogeneous catalyst for biodiesel synthesis, Bioresour. Technol. 102 (2011) 3610-3618.

[58] S.M. Smith, C. Pathum, V. Weeramongkhonlert, C.B. Smith, S. Chaveanghong, P. Ketwong, et al., Transesterification of soybean oil using bovine bone waste as newcatalyst, Bioresour. Technol. 143 (2013) 686-690.

[59] M. Farooq, A. Ramli, A. Naeem, Biodiesel production from low FFA waste cookingoil using heterogeneous catalyst derived from chicken bones, Renew. Energy 76 (201) 362-368.

[60] P.L. Boey, G.P. Maniam, S.A. Hamid, D.M.H. Ali, Utilization of waste cockle shell (Anadara granosa) in biodiesel production from palm olein: optimization using response surface methodology, Fuel 90 (201) 2353-2358.

[61] B. Jutika, A.J. Thakur, D. Deka, Solid oxide derived from waste shells of Turbonillastriatula as a renewable catalyst for biodiesel production, Fuel Process. Technol. 92(10) (2011) 2061-2067.

[62] M.S. Islam, M.A. Rouf, Waste biomass as sources for activated carbon production: A Review, Bangladesh J. Sci. Indust. Res. 47 (2012) 347-364.

[63] B.H. Hameed, C.S. Goh, L.H. Chin, Process optimization for methyl ester production from waste cooking oil using activated carbon supported potassium fluoride, Fuel Process. Technol. 90 (200) 532-1537.

[64] L. Riadi, E. Purwanto, H. Kurniawan, R. Ktaviana, Effect of bio-based catalyst inbiodiesel synthesis, Procedia Chem. 9 (2014)172-181.

[65] H. Amani, Z. Ahmad, M. Asif, B.H. Hameed, Transesterification of waste cooking palm oil by MnZr with supported alumina as a potential heterogeneous catalyst, Jour. Indust. Eng. Chem. 20 (2014) 4437-4442.

[66] A.N. Phan, T.M. Phan, Biodiesel production from waste cooking oils, Fuel 87(1718) (2008) 3490-3496.

[67] M.D. Serio, M. Cozzolino, R. Tesser, P. Patrono, F. Pinzari, B. Bonelli, E Santacesaria, Vanadyl phosphate catalysts in biodiesel production, Appl. Catal. A Gen. 320 (2007) 1-7.
[68] F. Guo, Z. Fang, C.C. Xu, R.L. Smith, Solid acid mediated hydrolysis of biomass for producing biofuels, Prog. Energy Comb. Sci. 38 (2012) 672-690.

[69] D. Junjiao, Y. Yi, S. Veena, J.K. Rakesh, Transforming waste into carbon-based nanomaterials, Carbon 96 (2016) 105-115.

[70] S.N. Alam, N. Sharma, L. Kumar, Synthesis of graphene oxide (GO) by modifies hummers method and its thermal reduction to obtain reduced graphene oxide, Graphene 6 (2017) 1-18.

[71] B.C. Brodie, On the atomic weight of graphite, philosophical transactions, Royal Soc. Lon. 149 (1859) 249-259.

[72] N.I. Zaaba, K.L. Foo, U. Hashima, S.J. Tan, W.W. Liu, C.H. Voon, Synthesis of graphene oxide using modified hummers method: solvent influence, Procedia Eng. 184 (2017) 469-477.

[73] Y.Zhu, S. Murali, W. Cai, X. Li, J.W. Suk, J.R. Pott, R.S. Ruoff, Graphene and graphene oxide: synthesis, properties, and applications, Adv. Mater. 22 (2010) 3906-3924.

[74] O. Moradi, V.K. Gupta, S. Agarwal, I. Tyagi, M. Asif, A.S.H. Makhlouf, H. Sadegh R.S. Ghoshekand, Characteristics and electrical conductivity of graphene and graphene oxide for adsorption of cationic dyes from liquids: kinetic and thermodynamic study, Jour. Ind. Eng. Chem. 28 (2015) 294-301.

[75] T.K. Kumar, D.S. Kumar, S. Manivannan, Effect of functional groups on dielectric, optical gas sensing properties of graphene oxide and reduced graphene oxide at room temperature, RSC Adv. 5 (2015) 10816-10825.

[76] R.S. Edwards, K.S. Coleman, Graphene synthesis: relationship to applications, Nanoscale 38 (2013) 38-51.

[77] M.C. Nongbe, T. Ekou, L. Ekou, K.B. Yao, E.L. Grognec, F.X. Felpin, Biodiese production from palm oil using sulfonated graphene catalyst, Renew. Energy 106 (2017) 135-141.

[78] C. Jun, Q. Yi, Z. Jie, H. Rui, Y. Weijuan, F. Zhentao, Conversion of lipids from wet microalgae into biodiesel using sulfonated grapheneoxide catalysts, Bioresour. Technol. 244 (2017) 569-574.

[79] C. Jun, Q. Yi, H. Rui, Y. Weijuan, Z. Junhu, C. Kefa, Biodiesel production from wet microalgae by using graphene oxide as solid acid catalyst, Bioresour. Technol. 221 (2016) 344-349.

[80] A.N. Shahid, H. Saira, A.A. Rashid, F. Khawar, F. Naveed, Y. Farida, S. Sadaf, Synthesis of multi-walled carbon nanotubes and their application in resin based nanocomposites, J. Phys. Conf. Series 439 (2013) 2-9.

[81] J. Prasek, J. Drbohlavova, J. Chomoucka, J. Hubalek, O. Jasek, V. Adam, R. Kizek, Methods of carbon nanotubes synthesis- Review, J. Mater. Chem. 40 (2011) 15872-15884.

[82] P.M. Alexander, M.W. Eugene, O.L. Raouf, Growth of carbon nanotubes by arc discharge and laser ablation, in carbon nanotubes, CRC Press, Florida, USA 2004, pp.65-97.

[83] M. Meyyappan, Growth in carbon nanotubes, CRC Press, Florida, USA, 2004, pp.99-116.

[84] Q. Shu, G. Tang, F. Liu, W. Zou, J. He, C. Zhang, L. Zou, Study on the preparation, characterization of a novel solid Lewis acid $\mathrm{Al}^{3+}-\mathrm{SO}_{4}{ }^{2-} /$ MWCNTs catalyst and its catalytic performance for the synthesis of biodiesel via esterification reaction of oleic acid and methanol, Fuel 209 (2017) 290-298.

[85] A. Deep, A.L. Sharma, P. Kumar, Lipase immobilized carbon nanotubes for conversion of Jatropha oil to fatty acid methyl esters, Biomass Bioenergy 81 (2015) 83-87. 